\title{
Shopping and chatting: Reports of tourist-host interaction in The Gambia
}

\author{
SARAH LAWSON and ADAM JAWORSKI
}

\section{Abstract}

As it becomes continually easier, at least technologically, for people to move around the world, so the growing numbers of global tourists, in their search for constantly novel experiences (Urry 2002), travel to destinations which are increasingly exotic and distant to them, not only geographically, but also in economic, social and cultural terms. This, in turn, brings them into contact with people from these very different cultures and societies. This paper examines interactions between tourists and hosts in The Gambia, a 'winter sun' package holiday destination in West Africa. To investigate the nature of such interactions, 20 'communication diaries' were completed by a group of British tourism students during their week-long field trip to The Gambia and followed up by small group discussions with some of the participants. The students were asked to record as many individual interactions with Gambians as possible noting the following information: Time; Place; Situation; Interlocutor; Languages spoken; Topics; Result of interaction; Perceptions of interactions. 194 interactions were recorded. Many of the interactions were 'transactional' in that tourism workers treat them as potential sources of income. However, their tenor is predominantly 'personal' as they were full of phatic communion and chatting. Central to the tourist experience in The Gambia is the role of the 'bumsters' due to their mediating function between the tourists and other Gambian people. The omnipresence of the 'bumsters' in all tourist areas and their constant 'pestering' of tourists is initially annoying to the latter but also acts as a catalyst in encouraging contact with other Gambians by familiarising tourists with local people. We conclude by discussing our findings in the context of the global economies of tourism.

\section{Introduction}

One of the principal characteristics of the modern world is its globalization, i. e. increasing fluidity and interconnectedness of movement of peo- 
ple, information and finance (see, e. g., Appadurai 1990; Bauman 1998; Held and McGrew 2003). Thus, as it continues to become technologically easier for people to move around the world (Bauman's travellers by choice, i. e. tourists, as opposed those whose mobility is enforced, i. e. refugees or vagabonds), so the growing numbers of global tourists, in their search for constantly novel experiences (Urry 2002), travel to destinations which are increasingly exotic and distant to them, not only geographically, but also in economic, social and cultural terms. Moreover, as increasing numbers of people living in modern societies expect to travel for leisure (Urry 2002), holidays have become as much a signifier of cultural and economic capital (Bourdieu 1991) as traditional status symbols such as cars and houses.

Our expectations of what a destination is like (or should be like) are very much shaped by the images we are accustomed to seeing portrayed in the media and the tourist industry (e. g. holiday brochures). Although we have access to far more information about the rest of the world than ever before, this information is predominantly provided in a decontextualised manner which rarely gives a full picture of, or background to, the situation being described (Benthall 1993; Morley 1992). Thus, when we book a holiday, we purchase a 'product' based on decontextualised snapshots in brochures or soundbites in TV programmes; we may think we know what places are like before we go but this may well not be the case.

One of the classic definitions of tourism offered by Urry (2002) is premised on a distinction between work/everyday life and leisure/holidays, i. e. breaking from the routine, not being at work or living our ordinary life. Part of the product to be consumed on holiday is dépaysement, or a (slightly disorienting) change of scenery which may include, among other factors, the physical setting, climate, cuisine, as well as people. Contact with host communities can thus be construed as a fundamental part of the tourist experience, which is reinforced, for example, by travel guides and TV travel programmes regularly proffering advice about how best to communicate with 'the locals'. Indeed, even if they choose to spend the majority of their holiday in the hotel compound, most tourists at least venture out into the host community to do some shopping, thereby engaging in service encounters and small talk with hosts, and some enter into more extended exchanges with their hosts. Arguably, it is largely through this contact that tourists' perceptions of the country and its people are formed, and the narratives of their travel - to be recounted on their return - are developed.

The aim of the current study is to examine the nature of such touristhost interactions, and their perception by the tourists, using the reflections of British visitors to The Gambia reported in communication diaries and small group interviews. A rudimentary introduction to The Gambia 
as a tourist destination is first provided, followed by a presentation of the communication diary methodology. We conclude the paper by reflecting on our findings in the context of globalisation.

\section{The Gambia as a tourist destination}

The Gambia is a major, principally winter, 'sun-sea-sand' tourist destination in West Africa, attracting approximately 100,000 tourists per year. As the total population of The Gambia is only 1.4 million, this number of visitors makes tourism a very important industry for the country, representing approximately 15 percent of its GNP. Moreover, it has been estimated that almost all Gambians have a family member involved in tourism (Sheikh Tejan Nyang, Gambia Tourism Concern, personal communication) a factor which also has wide-ranging social, economic and cultural ramifications for Gambian society (Brown 1993; Jamison 1999).

For British tourists, The Gambia markets itself as an exotic but accessible destination, being only six hours' flight from Europe, and in the same time zone as Britain. As a former British colony, the official language of The Gambia is English, although many indigenous languages are also spoken, the main ones being Mandinka, Fula, Wolof and Diola. The majority of tourists visiting The Gambia are British, and most of them are on 'winter sun' package holidays. Formerly marketed as 'The Smiling Coast', presumably to parallel other similar country/ place names in the region, such as Ivory Coast and (the former) Gold Coast, it is now promoted under the slogan 'Your Haven in Africa' (http://www.visitthegambia.gm, official site of The Gambia Tourist Authority), both expressions implying the safety and friendliness of the country. For many British tourists, their holiday in The Gambia is their first, and often the last, experience of an African country.

One of the most striking features of The Gambia as a tourist destination is the pervasiveness of interaction between tourists and members of the local community. A major tourist activity is visiting craft markets to look at and sometimes buy local crafts, negotiating with the stall holder the while (see Jaworski et al. forthcoming). On leaving their hotels, tourists are approached by (generally) young local people offering to show them around, take them bird-watching, to various other tourist attractions, to restaurants, or even to their family compounds. Strolling along the beach, the tourist is also met by young people wanting to chat and accompany them on their walk. These people are commonly referred to as bumsters. Clearly, all of these encounters need to be treated predominantly as a type of service transaction. Local people, even those described as bumsters, who approach tourists and offer what seems like a 
social encounter, do that as part of their 'trade', and often count on some kind of material reward from the tourist in exchange for some informal guiding or simply for spending time together (Adama Bah, Gambia Tourism Concern, personal communication). Tourists have varying reactions to these approaches and encounters and it is these reactions which we examine in more detail below.

\section{Participants and methodology}

The principal method used to collect data on tourist-host interactions in this study was the communication diary. In the same way as an ordinary diary is a record of the events experienced by the writer, a communication diary is a record of a participant's reports of their interactions over a given period of time, providing insights into these interactions across a wide range of situations, which may not otherwise be accessible to the researcher.

Participant diaries have proved to be a useful method of collecting data on participants' reports of their behaviour in a variety of fields (e. g. education: Bartlett 2004; medicine: Johnson and Bytheway 2001; literacy studies: Jones, Martin-Jones and Bhatt 2000). The communication diary methodology has been predominantly used for the study of issues of multilingualism such as code-switching and language choice in specific domains (e.g. Gibbons 1987; Lawson and Sachdev 2001; Pennington et al. 1992; Romaine 1983; Ure 1979). In our study, although one of the questions involved the issue of 'language spoken' in particular interactions, the main focus was not on language choice per se. Rather, we are more interested here in the relational aspects of communication, including our participants' perceptions and evaluations of their encounters with local people. In this sense, our use of the methodology is an adaptation of the traditional approaches focusing on message content as opposed to message form (Hymes 1972), as far as these two aspects of communication can be separated. Moreover, these diaries provide us with both quantitative data on the frequency of different types of interactions with different types of interlocutor and qualitative data on participants' perceptions of their interactions. This approach to diary data has not been very widely used in sociolinguistics (but see Jones et al. 2000). A further advantage of this methodology is that it tends to elicit data which are 'grounded [...] in identifiable events' (Jones et al. 2000: 345), and therefore less abstract than, say, questionnaire reports, thereby 'reduc[ing] the problem of accurate recall' (Johnson and Bytheway 2004: 202). Thus, although in some ways open to the same criticisms as other self-reported data (Bourhis 1983, 1984), communication diaries can nevertheless provide interesting and insightful data. 
For the purposes of this study, the diaries were completed by 20 students and lecturers in tourism at a British university on a one week field trip to The Gambia in March 2002. Participants were aged between 19 and 50; 16 were female and 3 male (one did not declare their sex). The structure of the diaries (see Appendix for a full version) requested participants to record the following information about each interaction: the time and place where the interaction occurred; the situation that they were in or the activity they were taking part in at the time; characteristics of their interlocutor, such as (estimated) age, sex and occupation; the languages spoken in the interaction; the topics spoken about, what happened as a result of the interaction - whether they bought the item their interlocutor was trying to sell, for example - and how they felt about the interaction.

Although our participants were in The Gambia primarily to study local tourism, they were asked to complete the diaries about the periods when they were not following their educational programme. Their role at the time of data collection could thus be described as tourists holidaying in The Gambia. In addition, SL accompanied the group on their trip and conducted several interviews with hosts, during which it became clear that this was indeed the way participants were perceived by their local interlocutors. Inevitably, a negligible amount of interactions reported occurred during the group's organised visits to institutions such as newspaper offices and schools.

A total of 194 interactions between tourists and hosts was recorded, ranging from 3 to 18 entries in individual diaries. Our analysis follows the traditional sociolinguistic components of speech (Hymes' 1972 SPEAKING acronym) in trying to tease out the most salient characteristics of the interactions. Initially, we focused on participant role, including who initiated the interaction, setting (place of interaction), key, norms of interaction, and topic. Several broad categories emerged from participants' initial descriptions of these elements of their interactions. These categories were then cross-tabulated as a way of addressing the classic sociolinguistic question of 'who speaks what to whom and when' (Fishman 1965), and finally examined in the light of the participants' self-reflexive comments on the interactions. In the extracts reproduced below we preserve original spelling and layout.

Several semi-structured interviews were carried out with some participants to elicit additional perceptions of their tourist experience of The Gambia. One of these interviews with four participants was audio-recorded, and illustrative excerpts from this interview are presented alongside the diary data. In addition to this, we rely in our descriptions and interpretations on our own notes from the field. 


\section{Shopping and chatting}

The first aspect of the diaries to be examined is the roles of interlocutors in the interactions. Major variation can only be observed in host roles, with the tourists assuming a monolithic identity as 'tourists'. Host roles reported in the communication diaries are presented in Table 1.

Table 1. Host roles reported in the diaries.

\begin{tabular}{llc}
\hline & Interlocutor & $\%$ of interactions reported \\
\hline 1 & Bumster & 21 \\
2 & Shopkeeper & 20 \\
3 & Hotel staff & 13 \\
4 & Service provider & 13 \\
5 & Bar/restaurant staff & 10 \\
6 & Beach/street seller & 10 \\
7 & Other & 13 \\
\hline
\end{tabular}

Our data show that the most common interlocutors were bumsters, defined in the following quote from the brochure of The Gambia Experience, a major UK-based tour operator specialising in The Gambia:

First time travellers are not always prepared for the culture shock awaiting them in a developing country. There is poverty and begging but in contrast there is also genuine hospitality. Outside hotels and on the beaches, visitors encounter Gambians making a living selling fruit, nuts and handicrafts. It is the ones trying to sell their services as unofficial guides, locally known as bumsters, that can be persistent to the point of nuisance and although they may be off-putting there is no cause for alarm. The Gambia Tourism Authority have made great strides in reducing the amount of bumsters, although there is more work to be done. They also offer rudimentary training for official guides to show tourists around the local area and are recognisable by their uniforms and identity cards. (The Gambia Experience brochure, November 2004October 2005: 7; our italics).

As evidenced by the fact that they warrant a specific mention in the tourism brochure, bumsters are a major feature of tourists' life in The Gambia. Immediately on leaving the confines of the hotel compound, tourists are approached by bumsters wanting to show them around, chat to them and become 'friends'. As mentioned in the brochure, tourists have varying levels of appreciation of these offers; some enjoy the attention and the company, and others find it rather oppressive. In this way, the quote above portrays bumsters as problematic, in contrast to other 
Gambians who sell fruit, nuts and handicrafts, whose activities are rather legitimised in the brochure.

Other major categories of interlocutors are 'shopkeepers' and 'beach/ street sellers', 'hotel staff', 'bar/restaurant staff' and 'service providers'. Several of these categories overlap to a considerable extent as in any classificatory exercise of this type. For example, the distinction between the categories of 'shopkeeper' and 'beach/street seller' is based on the former having fixed stalls or shops, with the latter having much smaller, often movable businesses, working as juice sellers on the beach or roadside fruit sellers. 'Hotel staff' are defined as such even if they were not working at the time of the interaction, if that is how the tourists came to know them and described them in their diaries. The category 'service provider' includes people selling a service rather than goods, e.g. taxi drivers, tour guides, doctors, people hiring out bikes. 'Other' refers to people who do not fit into any of the above categories, such as journalists, beggars, police officers or musicians. The list of interlocutors seems to confirm our expectation of the type of people tourists normally encounter and engage with while on holiday and reflects common tourist activities, such as buying souvenirs, eating and drinking out.

It should be noted that the boundaries between the categories of 'bumster' and others such as 'beach seller' are somewhat blurred, not least because many of the beach sellers are former bumsters, but also because, if the beach sellers move away from their goods/stall to approach tourists, they may well initially be mistaken for bumsters. This is due to the similarity in approach techniques between the two groups, where the tourist is approached with a series of questions, such as 'Good morning boss lady. From where [are you]? What is your nice name?', and it only becoming clear later in the conversation that the person is selling a service or some goods.

The second stage of analysis focused on the topics of conversations between tourists and hosts, listed below.

Table 2. Topics of interactions reported in the diaries.

\begin{tabular}{llc}
\hline & Topic & \% of interactions reported \\
\hline 1 & Tourist-oriented personal information & 20.0 \\
2 & Services/goods for sale & 19.8 \\
3 & Host-oriented personal information & 19.0 \\
4 & Tourist experience of The Gambia & 8.3 \\
5 & Greeting & 7.8 \\
6 & Culture and customs & 7.4 \\
7 & Request for friendship & 7.0 \\
8 & Other & 10.6 \\
\hline
\end{tabular}


As discussed in the case of host roles, topic categories emerging from participants' reports are also overlapping and fuzzy. Tourist-host interactions, not unlike other contexts of communication are polyfunctional (cf. Tracy and Coupland 1990), so the above tabulation is, again, based on the dominant and often multiple characterisations of individual encounters chosen by our informants. Any single interaction leading to an offer of a sale of any sort may start with a question about the tourist's well-being, experience of The Gambia, or some other enquiry. In fact, bumsters' or sellers' gambits involving a question about when the tourist arrived in The Gambia may be as much a 'friendly' opening as a way of gauging the tourist's naïveté as far as local trading practices are concerned (see also discussion of Interview Extract 1, below). Thus, our characterisation of 'topic' is based on as many themes as were reported by the informants for each interaction.

The examples of specific categories include:

1. tourist-oriented personal information: hosts' questions about tourists' place of origin/residence, occupation, family, and so on;

2. services/goods for sale: buying/selling goods at the craft market, beach/street stalls;

3. host-oriented personal information: tourists' questions about hosts' place of origin/residence, occupation, family;

4. tourist experience of The Gambia: how long the tourist has been in The Gambia, whether it is her/his first visit;

5. greeting: more or less elaborate exchanges of greeting formulae;

6. culture and customs: hosts explaining The Gambia to the tourists;

7. request for friendship: hosts asking tourists to 'keep in touch', to exchange addresses, to receive an invitation to the UK.

What is apparent in the above list of topic types (see Table 2) is that most of them $(1,3,4,5,7)$ represent phatic communion (Malinowski 1923) or small talk (Coupland 2000) rather than transactional (2) or referential talk (6), the former set corresponding to Halliday's (1978) interpersonal macrofunction of language, while the latter to his ideational, or referential macrofunction (see also Tracy and Coupland 1990). This may be a somewhat unexpected result in that, in what seem to be predominantly service encounters, the interactions proceed mostly along the lines of social talk. Of course, this is not to say that elements of phatic talk, mainly in the form of various politeness formulae, are not normally found in service encounters (see, for example, Aston 1988; Coupland and Ylänne-McEwen 2000; Kuiper and Flindall 2000), and specifically in tourist-host service encounters (Jaworski et al. forthcoming). However, what we see in our data is an uneven distribution of 
Table 3. Cross-tabulation of interactions by topic types and interlocutors (percentages).

\begin{tabular}{|c|c|c|c|c|c|c|c|}
\hline & \multicolumn{7}{|c|}{ Interlocutor occupation } \\
\hline & $\begin{array}{l}\text { Hotel } \\
\text { staff }\end{array}$ & $\begin{array}{l}\text { Shop } \\
\text { keeper }\end{array}$ & Bumster & $\begin{array}{l}\text { Bar/ } \\
\text { restaurant } \\
\text { staff }\end{array}$ & $\begin{array}{l}\text { Service } \\
\text { provider }\end{array}$ & $\begin{array}{l}\text { Beach/ } \\
\text { street } \\
\text { seller }\end{array}$ & Other \\
\hline $\begin{array}{l}\text { Tourist } \\
\text { oriented }\end{array}$ & 14.6 & 21.4 & 27.9 & 9.8 & 15.6 & 7.9 & 25.4 \\
\hline $\begin{array}{l}\text { Host } \\
\text { oriented }\end{array}$ & 25.0 & 8.3 & 18.9 & 4.9 & 6.7 & 31.6 & 34.9 \\
\hline $\begin{array}{l}\text { Request } \\
\text { for } \\
\text { friendship }\end{array}$ & 10.4 & 4.8 & 8.1 & 2.4 & 2.2 & 2.6 & 12.7 \\
\hline $\begin{array}{l}\text { Services/ } \\
\text { goods for } \\
\text { sale }\end{array}$ & 4.2 & 44.0 & 3.6 & 43.9 & 26.7 & 42.1 & 3.2 \\
\hline $\begin{array}{l}\text { T'st } \\
\text { experience } \\
\text { of The } \\
\text { Gambia }\end{array}$ & 8.3 & 9.5 & 13.5 & 4.9 & 2.2 & 7.9 & 7.9 \\
\hline $\begin{array}{l}\text { Customs } \\
\text { and } \\
\text { culture }\end{array}$ & 12.5 & 1.2 & 9.0 & 22.0 & 8.9 & 2.6 & 1.6 \\
\hline Phatic & 4.2 & 9.5 & 9.0 & 7.3 & 6.7 & 2.6 & 11.1 \\
\hline Other & 20.8 & 1.2 & 9.9 & 4.9 & 31.1 & 2.6 & 3.2 \\
\hline
\end{tabular}

different aspects of phatic and instrumental talk across different types of interlocutors. We examine this link by cross-tabulating topic types with host roles (see Table 3).

Perhaps predictably, transactional talk is clearly shown taking place between tourists and interlocutors such as Shopkeepers, Bar/Restaurant Staff, Beach/Street Sellers, and other Service Providers. Levels of phatic talk are high with all categories of interlocutor.

As is indicated in Table 3, bumsters initiate more phatic talk (i.e. our earlier topic types $1,3,4,5$ and 7 ; see Table 2) than any other category of interlocutor. A particularly striking feature of phatic interactions with bumsters is that they focus predominantly on the tourist. Laver (1981) proposes three types of speaker-listener orientations in small talk: self (e. g. " "Hot work this," "I do like a breath of fresh air," "My legs weren't made for these hills."' (p. 302), other (e. g. " "How's life/business/the wife/ the family?," "That looks like hard work," "Do you come here often?", (p. 302), and neutral (e. g. " Nice day," "What weather," "Frost tonight," 
"Nice party," "About time the trains were cleaned"” (p. 301). Laver also makes the following observation:

The pattern of choice of category that constitutes the polite norm is one where speakers who are well-acquainted can freely choose any category, but where non-acquainted speakers obey a constraint which depends on relative social status. The neutral category is available to speakers of any social status, but other-oriented phrases are politely available only to speakers of relatively higher status, and self-oriented phrases only to speakers of relatively lower status. (Laver 1981: 302)

In our data, three of our five phatic categories $(1,3,5)$ display Laver's other-orientation and are found at high levels in bumster talk, which may be read by tourists as bumsters' making claims to interactional power and dominance. This, in part, may contribute to the tourists' unease or downright hostility in talking to bumsters, at least initially. Furthermore, tourist-oriented talk, as defined earlier, concentrates on extracting what the hosts may perceive as 'free information' (cf. Lakoff 1974, following Goffman's 1967 notion of 'free goods', cited in Thomas 1985) about the tourists, i.e. asking questions without causing offence even to a stranger. However, as Thomas (1985) points out, the notion of what is an interactionally 'free' good may vary cross-culturally, and mismatches may lead to pragmatic failure. The following diary extracts illustrate some of these issues:

\section{(1) Diary Extract 1}

Communication diary 11; female aged 23

He asked me my name, age, where I lived what England was like

\section{(2) Diary Extract 2}

Communication diary 7; female aged 23

I felt the conversation was all about me he didn't inform me much about his culture

As can be seen from the two extracts above, tourist-oriented phatic talk can be 'innocuous' and not lead to any specific evaluative comments on the part of the tourist (Diary Extract 1), or it may create a sense of unease as expressed in Diary Extract 2. In the latter example, our participant comments, albeit indirectly, on the lack of reciprocity in the exchange of information between herself and a bumster. Interestingly, small talk is here construed not just as talk about 'nothing', but as more 
or less successful 'information exchange'. It is this sense of exchange and one-sidedness of the flow of information that is likely to create unease among tourists.

A further category of other-oriented phatic communion is 'request for friendship', where hosts ask for tourists' contact details in order to remain in touch once the tourist has returned home. Again, these can be reported as innocuous, but can also be perceived to be invasive as in Diary Extract 3 below:

\section{(3) Diary Extract 3}

Communication diary 18; female, aged 22

[talked about] me!! + how he gave his heart to me and when he could come to England! made my excuses and left as his crap was too much!

In the above example, apart from reporting tourist-(i.e., self-)oriented small talk, she also highlights a not atypical approach by a bumster (most of whom are male) playing with slightly risqué versions of small talk including flirting and sexual innuendo. Both aspects of the approach are marked for strong negative evaluation indicated by double exclamation marks after 'me', and the use of the expletive in the metapragmatic comment about the bumster's advances.

Finally, other-orientation in bumster talk is evident in Diary Extracts 4 and 5, which inquire about tourists' experience of Africa and The Gambia. This is particularly useful information for tourism workers in order to assess the best way to approach their clients:

(4) Diary Extract 4

Communication diary 16; female aged 21

[asked] What I want to do, if I have been to Africa before?

(5) Diary Extract 5

Communication diary 17; female aged 21

[asked] where we're from, age, how long we're here for, etc

All of the above extracts exemplify types of situations in which tourists are approached by local people and coerced into disclosing personal information of one kind or another. This may generate negativity among tourists, which is reflected in a number of statements made by our participants in the diaries, especially in the earlier part of their stay in The Gambia. Consider the following example: 
(6) Diary Extract 6

Communication diary 18; female aged 22

Never thought it would be so difficult to have a conversation. Most of the men are only interested in either our address or being special friend.

The above extract demonstrates some of the common sentiments found across the diaries. First is the complaint that the bumsters are intrusive in that the information they request from the tourists may not be as 'free' as they assume. Several of our informants report leaving their home or email addresses with the bumsters, but they may do so due to feeling pressurised. The interrogative nature of bumsters' speaking style without disclosing as much personal information leaves tourists with a sense of lack of reciprocity (cf. Diary Extract 2) reminiscent of Tannen's (1984) discussion of 'machine gun' conversational style among friends. 'Requests for friendship', which, as has been noted, are often accompanied by sexual innuendo and flirting, are also sometimes reported as undesirable (cf. Diary Extract 3).

'Tourist experience of The Gambia', which is another category of tourist-oriented phatic talk may add to the perceived pressure of the interrogative nature of these encounters (cf. Diary Extracts 4 and 5), and again, the underlying function of these questions may be transactional. Information as to whether the tourist has just arrived in The Gambia or whether s/he has spent a considerable amount of time in the country could be seen as essential information for tourism workers, as it provides an indication of how aware tourists are of customs and prices in The Gambia, or how easy it may be to entice them to a money-making activity. Indeed, as can be seen in Interview Extract 1 below, our participants report being specifically warned in the tour operator's introductory talk on the airport transfer bus to be wary of such questions and to conceal the fact that they had just arrived in The Gambia for the first time:

\section{(7) Interview Extract 1}

Alison, Barbara, Cheryl and Dawn (pseudonyms) talking to SL at Sanyang Nature Camp, The Gambia, on the evening of Day 4 of their weeklong trip.

1 SL so (.) what kind of things did she [tour operator] say about (.) the bumsters

2 or the locals that (.) you were gonna meet?

3 C that you've got to lie to them (.) that you've gotta say that

4 D

5 C that you've been here before er<smiles>C1C[AsH2]C1</smiles> 


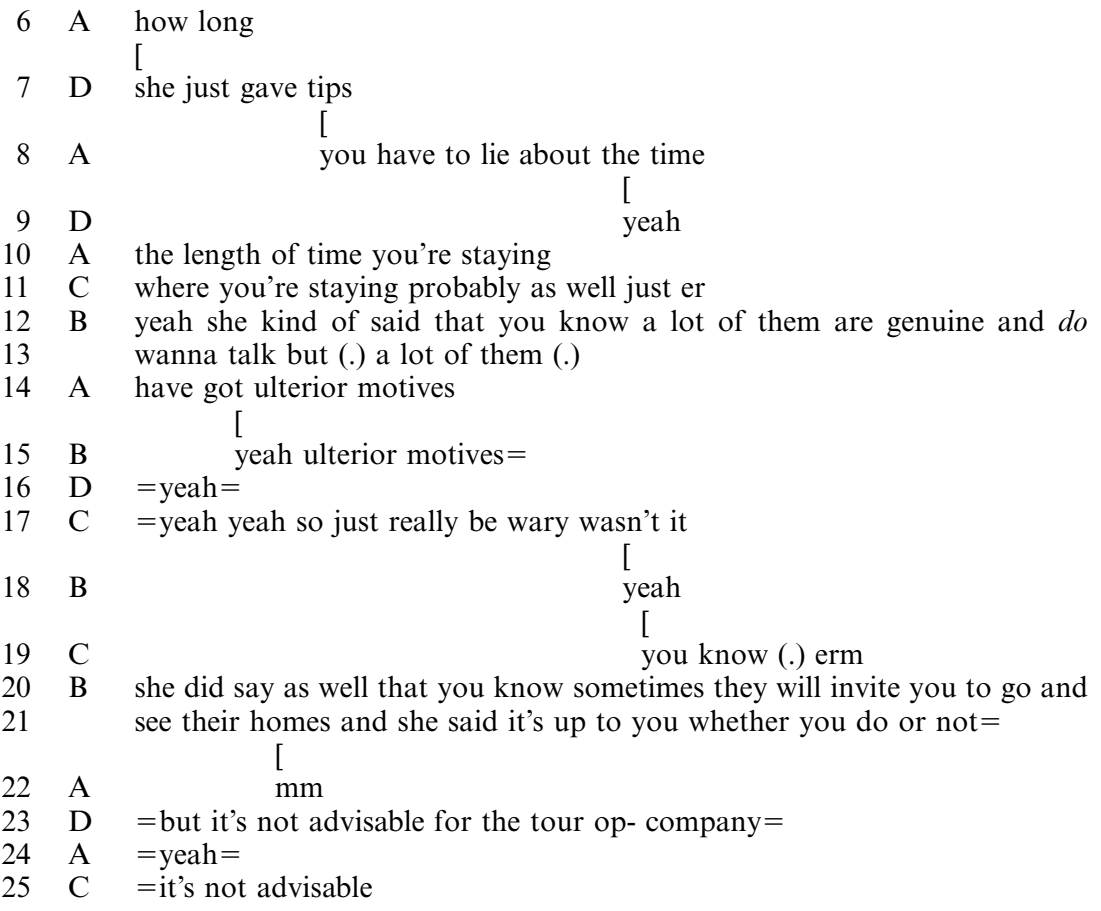

The above extract is illustrative of a broader role the tourism industry, especially the western tourism companies and travel media, play in the tourists' pre-visualising their travel destinations and hosts (as mentioned in our Introduction). As far as these participants' initial image of bumsters and other local people in The Gambia is concerned, it is construed around the notions of mistrust and deceit (lines 3-11) and disingenuousness (lines 12-15). In consequence, tourists are advised to 'be wary' of interpersonal contact with local people (line 17), and avoid what, ironically, is probably considered by most tourists to be the ultimate authentic tourist experience: a visit to a host's home. It is probably not surprising that apart from some of the pragmatic mismatches in what is appropriate communication between hosts and tourists, such prejudicial construal of hosts by the tourist industry results in overall negative reactions of tourists to the Gambians encountered in the first few days of the holiday.

Throughout the extracts, it is interesting to note participants' uniformity of opinion and shared beliefs on their Gambian experience, and the similarity in the trajectories of their tourist ideologies vis-à-vis their Gambian hosts. This can also be seen in the high levels of collaborative overlapping speech (note, especially the overlap of 'ulterior motives' in 
lines 14 and 15), and supportive back-channeling (e.g., 'mm'; 'yeah') found in the conversations.

Table 4 demonstrates the frequency with which different types of talk are initiated by different interlocutors, as interpreted from the reports of the interactions in the diaries. It can be seen that the tourists initiate conversations when ordering food and drink or inquiring about items they might want to buy. Conversely, it is clear that shopkeepers and street sellers also initiate interactions to try and sell their goods. However, where a host initiates a conversation just for the purposes of chatting, the host is generally a bumster. The evaluative comments by the informants indicate that the frequent initiation of phatic talk by the bumsters is perceived as invasive, one informant referring to it as 'initially alarming ... "forward"ness' (Communication diary 1, female aged 45).

Table 4. Cross-tabulation of frequency of initiation of different types of talk by different interlocutors.

\begin{tabular}{|c|c|c|c|c|c|c|c|}
\hline & \multicolumn{7}{|c|}{ Interlocutor occupation } \\
\hline & $\begin{array}{l}\text { Hotel } \\
\text { staff }\end{array}$ & $\begin{array}{l}\text { Shop } \\
\text { keeper }\end{array}$ & Bumster & $\begin{array}{l}\text { Bar/ } \\
\text { restaurant } \\
\text { staff }\end{array}$ & $\begin{array}{l}\text { Service } \\
\text { provider }\end{array}$ & $\begin{array}{l}\text { Beach/ } \\
\text { street } \\
\text { seller }\end{array}$ & Other \\
\hline $\begin{array}{l}\text { Host } \\
\text { approach: } \\
\text { chat }\end{array}$ & 4.2 & 2.9 & 59.5 & & 4.2 & 37.5 & \\
\hline $\begin{array}{l}\text { Host } \\
\text { approach: } \\
\text { business }\end{array}$ & 4.2 & 32.4 & 21.6 & & 16.7 & 29.4 & 4.2 \\
\hline $\begin{array}{l}\text { Hotel } \\
\text { staff } \\
\text { working }\end{array}$ & 8.3 & & & & & & \\
\hline $\begin{array}{l}\text { Hotel } \\
\text { staff } \\
\text { chatting }\end{array}$ & 8.3 & & & & & & \\
\hline Tourist & 29.2 & 17.6 & & 64.7 & 20.8 & 47.1 & 12.5 \\
\hline $\begin{array}{l}\text { Tour } \\
\text { guide } \\
\text { working }\end{array}$ & & & & & 25.0 & & \\
\hline Unknown & 45.8 & 47.1 & 18.9 & 35.3 & 33.3 & 23.5 & 45.8 \\
\hline
\end{tabular}

The combination of the initiation of phatic talk, tourist-orientation of phatic talk, and the industry's stereotyping of hosts may be the main factors responsible for the tourists' negativity towards the bumsters. In Laver's terms, the tourists are positioned as subordinate recipients of sociability, despite their economic and historic (colonial) dominance pre- 
defining their role of tourists in The Gambia. Likewise, the preponderance of requests for personal information in bumsters' questions gives them a dominant edge over the tourists (cf. Wolfson 1976; Briggs 1986).

The levels of irritation reported being caused by personal talk initiated by the bumsters contrast with comments about interactions with hotel staff, who tend to get to know clients in the hotel in non-threatening service encounters and then become friends (see also Diary Extract 10 below). In addition, hotel staff and beach/street sellers display a significantly higher level of host-oriented phatic talk, with the former group displaying a low level of transactional talk in contrast to the latter group. 'Irritating' tourist-oriented phatic talk is also quite prominent in shopkeepers but it is counterbalanced by a high level of transactional interactions, which are practically missing from bumster talk.

Participants were also asked to record how they felt at the end of their interaction with an interlocutor. In some cases, this took the form of a comment on how successfully they felt they had bargained, whether they had learnt something from the interaction and, in some cases, that they had felt harassed by the interaction. Overall, reported attitudes to interactions were positive (70.6\%), although attitudes towards interactions with bumsters were somewhat less positive $(62.5 \%)$. Participants made comments such as

\section{(8) Diary Extract 7}

Communication diary 17; female aged 21

[I felt] annoyed but felt sorry for him. All the boys say the same things

where the bumster in question had asked if he could accompany the participant back to England, and wanted an address (see also Extracts 3 and 6 , above).

The category 'Greetings' appears relatively frequently, possibly due to the specificity and salience of this speech act, which is characteristic of, and arguably essential to, interactions in West Africa (Irvine 1974; Youssouf et al. 1976). Here, too, may be the cause of some resentment felt by tourists towards the bumsters whose extended greeting sequences common in West Africa may be perceived as an imposition. In other words, the mismatch between the West African and Western/European greeting patterns may lead to cross-cultural pragmatic failure and mutual negative stereotyping (cf. Thomas 1985; Scollon and Wong-Scollon 1990). Moreover, Youssouf et al. (1976), using Sacks' (1972) terminology, argue that in order to initiate an interaction with a stranger, one needs a 'ticket', i.e. a reason, for interacting with them. The bumsters' aim of chatting and becoming friendly with a stranger, i. e. the tourist, and thus 
their attempt to initiate a friendly chat, would appear not to constitute a 'ticket' in European terms. Bumsters also often adopt a very informal form of address when approaching tourists, which some tourists may feel to be inappropriate coming from strangers. Participants feel more positive about interactions with other interlocutors, such as shopkeepers and service providers, as there appears to be a clearer transactional objective legitimising the conversation.

Even so, although initially somewhat nervous of talking to hosts and especially to bumsters, participants' comments indicate that they gradually became accustomed to dealing with this group:

\section{(9) Diary Extract 8}

Communication diary 17; female aged 21

[Conversations were] ... limited to start with, always asked the same questions, and so it was really boring to talk to the bumsters $[\ldots$ later on, however ...] conversations were more interesting as after being here for a while you decided who you wanted to talk to a bit more and we tried to move away from the same boring questions.

Some participants found that adopting a more relaxed approach to interactions with hosts also had the effect of improving the quality and enjoyability of the interactions, as exemplified in Diary Extracts 9, 10 and 11:

(10) Diary Extract 9

Communication diary 6; male aged 21

I discovered towards the end of the field study that if I smiled at people and was polite and chatty that they left me alone quicker and I enjoyed my conversations with them, whereas previously my mistrust because of advice given before we arrived made me think of the people with whom I spoke as a nuisance and that they were 'after something', whereas this was not generally the case.

In addition, contact with the bumsters seems to serve as a springboard to interactions with other Gambians, in that participants not only began to learn about Gambian culture and customs, but also gained confidence in chatting to other locals (see Diary Extracts 10 and 11, below).

\section{(11) Diary Extract 10}

Communication diary 14; female aged 20

At first speaking/communicating with Bumsters was difficult. Once used to them, they were very interesting to talk with and I learnt much from them about Gambian culture and customs. 
After the conversations with the Bumsters, I felt more at ease to communicate with the other locals.

(12) Diary Extract 11

Communication diary 11; female aged 23

Period A:

Finding it quite hard to get rid of the bumsters, who constanly want to talk to you. It's very difficult to be firm but fair with them I feel like I'm being rude but I can't give everyone what they want! Period B:

Getting better, I can understand now how to deal with the bumsters, it's nice talking to them however I now know how to get rid of them if need be. I have relaxed more and feel more comfortable chatting to strangers.

Having been approached by bumsters on several occasions, and become more familiar with Gambian interactional norms, tourists find they are more successful at interacting with their hosts. Participants report feeling more confident in engaging in conversations with other people. Moreover, several informants mentioned the quasi-pedagogic role that bumsters adopt. As a result of the above analysis, it may be possible to redefine bumsters as cultural mediators, representing an accessible way into Gambian society for tourists who might otherwise seek out or experience very little of their host culture during their holiday. This is confirmed by the discussion in Interview Extract 2, below. Here, talking to locals is seen as an essential and enjoyable part of the holiday, not only because the tourist can learn new things but also, given the 'packaging' of the tourist experience by the industry, it is only through talking to people that tourists will 'know' where in the world they are:

\section{(13) Interview Extract 2}

Participants and situation as Interview Extract 1

1 D you know when you actually do get chatting to the locals and that's

2 B $\quad$ [

3 D when you think fully think yeah I'm actually here in Gambia and I'm you

4 know I'm ((laughs)) in Africa not just lying on a beach

5 B

yeah

[

anywhere

$6 \quad \mathrm{D}$

you could be you know it is good I mean you have to talk at it d'you know 


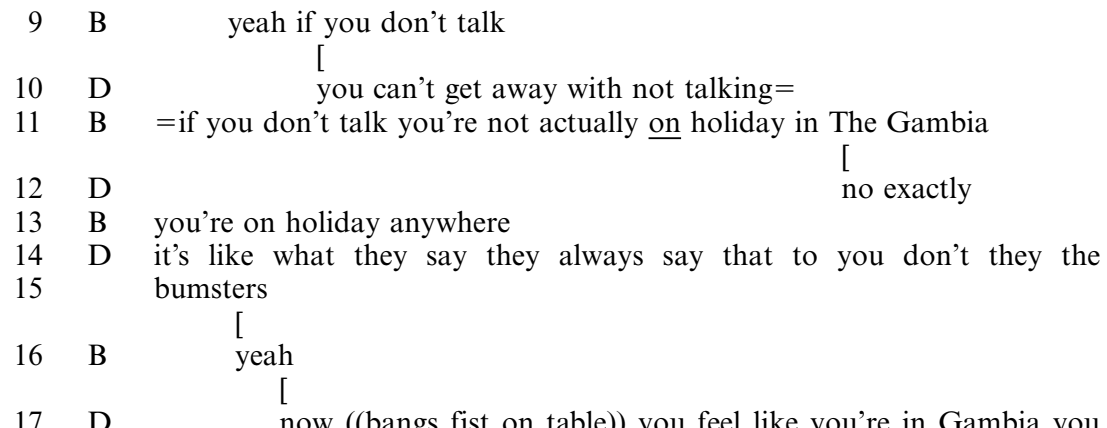

21 B yeah $\mathrm{mm}$

22 D you know it's great when you get talking past the banter

Interview Extract 2 indicates a shift in the tourists' reported perception and attitude of hosts in The Gambia. We would suggest that this extract is indicative of the principle: Familiarity breeds contentment as well as understanding and friendliness (cf. 'when you get talking past the banter', line 22). Besides, what these participants seem to suggest in their metapragmatic comments of their interactions with hosts is the sociolinguistic orthodoxy of talk and interaction being the sites of constructing and maintaining their personal identities as tourists ('yeah I'm actually here in Gambia', line 3), creating for themselves a sense of place ('not just lying on a beach anywhere', lines 4-6), and, as we would argue, a source of future narratives of the tourist experience (cf. Jaworski et al. forthcoming).

Some informants also report going a step further and forming friendships with Gambians, as illustrated in Diary Extract 12.

(14) Diary Extract 12

Communication diary 16; female aged 21

The locals are welcoming and friendly. You do however have the odd few who do hassle you too much. But once you have talked to the locals for a bit, you view changes about them. I enjoyed meeting the locals and have made some friends in the Gambia now.

Thus, over the period of their stay in The Gambia (even as short as a week), it is possible to see an increased level of cross-cultural awareness (Hanvey 1979) developing in participants' comments. Some participants report being guided through their holiday in a way that is reminiscent 
of holidays being construed as the liminal rites of passage and pilgrimages (Turner 1969, 1974; Graburn 1989), with bumsters and other local people acting as the cultural brokers between tourists and the local community at large ('he's been with us all the way through', see Interview Extract 3, lines 9-10).

Interestingly, in the next extract, the interviewees go as far as referring to making friends among the bumsters (see Interview Extract 3, line 1, below) which may indicate a more accommodating stance towards the bumsters (cf. 'Request for friendship' category of talk discussed above). However, when A refers to the idea of 'adopt[ing] a friend' (line 4), a power imbalance in the relationship is suggested in that 'friendship' turns out to be a result of a one-sided decision on the part of the tourist:

\section{(15) Interview Extract 3}

\section{Participants and situation as Interview Extract 1}

1 B we've we've actually made a friend

2 D we've yeah

3 C/B $\quad$ yeah

4 A we adopted a friend on our first night

5 D yeah

6 C yeah

7 A we got quite drunk ((laughs))

8 B yeah

9 A and we thought that he was very nice and he's been with us all the way 10 through

11 C [ he's good they've

12 really looked after us

13 A he's taken us down the beach he's taken us to his home

14 B $\quad$ [ we went out we went

15 out to a very very good nightclub

16 A he's taken us to a nightclub

17 B he looks after us really really well

Arguably, despite being branded as the 'bad guys' to be wary of (see above), the bumsters offer the tourists the friendliness that also features so prominently in the brochures about The Gambia. However, what seems to be going on here is an economic exchange valid only for the duration of the tourists' visit to The Gambia. It was confirmed in our numerous observations that bumsters effectively commodify their friendliness for the tourists and sell their services as unofficial guides, in- 
structors, interpreters and protectors from other bumsters, vendors and service providers in exchange for drinks and meals, and sometimes offers of small gifts or money. And despite there often being an optimistic agenda of maintaining contact after the tourists have returned home, with only a few exceptions, the relationships which develop between tourists and bumsters are essentially fleeting (cf. Jaworski et al. 2003). More lasting friendships would require more time and less (economic) distance between the two parties. This point is in fact made in the next interview extract, following on from Extract 3, above:

\section{(16) Interview Extract 4}

\section{Participants and situation as Interview Extract 1}

1 SL do you think you'll keep in touch with the people that you've come into 2 contact with (.) like your friend you mentioned?

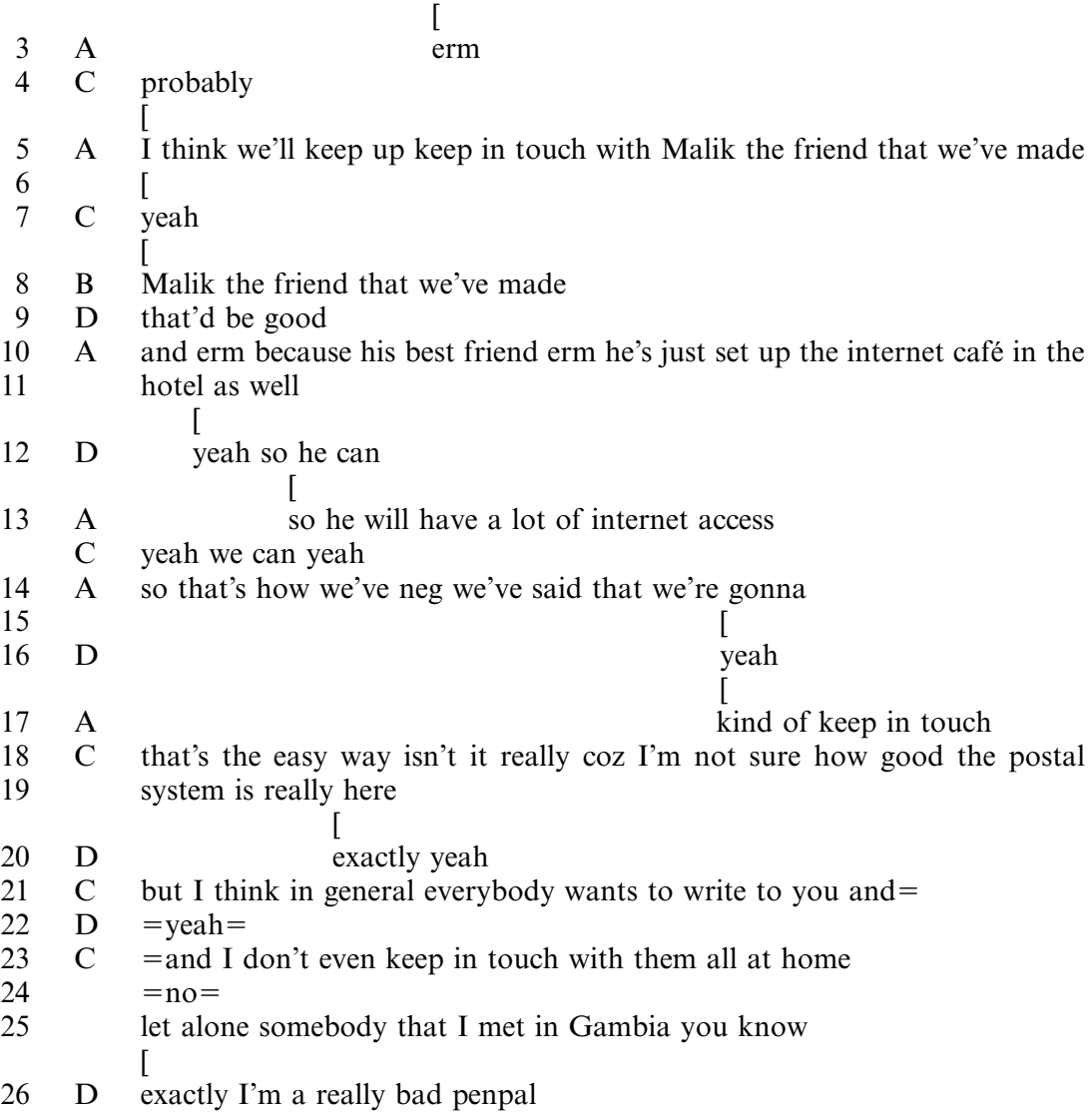


27 C so I'd say no personally myself I wouldn't I wouldn't bother (.) I've done

28 it too many times before and you know $=$

29 D $=$ yeah $=$

$30 \mathrm{~B}=$ that's true

31 D so you know what's gonna happen don't you=

$32 \mathrm{C}=$ yeah (.) and it's not very likely that I'll probably come back to Gambia 33 I don't know and if I was d'you know that might be a very long time away 34 and therefore I wouldn't

Interview Extract 4 also exemplifies the disparity in access to the logistics necessary to keep in touch with new friends. Malik's friend has an internet café so it may be possible for the participants to stay in contact with him. Without this, contact would be difficult. Malik apart, however, the group are pessimistic (realistic?) about the future of maintaining contacts on their return to the UK (lines 23-31). What is interesting here is the types of accounts given by the participants to rationalise the fact that they are unlikely to continue contact with Malik (or other Gambian 'friends'): being a bad penpal (line 26), being unable to maintain longdistance relationships (lines 23, 25, 27-28), low likelihood of visiting The Gambia again soon (lines 32-34). All of these accounts place the responsibility for not continuing the friendships started during the holiday on the tourists themselves. Again, this demonstrates the tourists' implied domination of their relationships with the hosts by being able to choose to come into or opt out of a relationship as they will. The above comments also support the view that the tourist-host relationships are like the tourist identity: transient and fleeting (cf. Jaworski et al. forthcoming). They are an important part of the holiday, but, like the tourist identity, recede into narratives and souvenirs on return to 'real' life.

\section{Conclusion: Tourist-host interaction in The Gambia and global tourism}

The interactions reported in these communication diaries and participant interviews represent a wide range of the kinds of tourist-host exchanges experienced by international tourists and their hosts. Additionally, by using the self-reflexive diary format, it is possible to see the development of the tourists' perceptions of their interactions as they become more experienced in interaction with their Gambian hosts.

These interactions between Gambian hosts and British tourists are also invariably conducted through English. Indeed, participants reported very sketchy knowledge about indigenous Gambian languages. As is typical of so much 'international' tourism, this suggests an accommodating orientation of hosts towards tourists; even if English continues to be a reminder of colonial subjugation, nowadays it appears to be a useful 
instrument attracting a specific group of tourists/clients (see Lawson 2002).

In terms of tourist-host relations, The Gambia, not unlike most other tourist destinations in the world, is marketed as a 'friendly' place. Indeed, our data suggest that having overcome initial prejudices, the tourists can derive much pleasure and positive intercultural experience from their encounters with local people. It is also clear that hosts benefit economically from the tourists' purchases of goods, services and offers of drinks and food. What we want to argue here, however, is that the obvious economic and socio-political asymmetries between British tourists and Gambian hosts, inevitably preclude these fleeting encounters from becoming lasting friendships based on symmetry and reciprocity. In other words, the actual interactions between hosts and tourists in The Gambia highlight the shared ideology of globalisation despite the actual flow of people (Appadurai 1990) being sustained and sustainable only in one direction: from the rich north to the poor south. As Blommaert puts it: "Inequality, not uniformity, organizes the flows" (2003: 612; italics in original).

This situation may be explained by the fact that the tourists, coming from a 'modern' society, have access to the accompanying fluidity of movement (Bauman 2000), but the Gambians do not. Thus, although the Gambian hosts (most notably the bumsters) seem to buy into the common ideology (mythology?) of global flows through what is defined here as 'requests for friendship', implying extended contact culminating in visiting the UK, these visits rarely materialise. In this way, we suggest, the notion of the 'global village' holds sway over both tourists and hosts, but only in their mutual engagement in the discourse. Indeed, while many tourists may perceive these conversations as purely phatic, or as local flavour, many bumsters have greater aspirations (see Brown 1993). Thus, the interactions reported to us by the visitors to The Gambia remain part of the tourist consumption of the destination, in which the locals' displays of friendliness, cultural expertise and mediation between tourists and other members of the local community are economic transactions premised on the regional inequalities of global capitalism.

The economic inequality underlying tourist-host interactions in The Gambia is further exemplified by the fact that the onus is clearly on the hosts to make friends: the initial approach is generally made by the hosts, with much of the initial conversation oriented towards the tourist. It is up to the hosts to convince the tourists to speak to them, and to help the tourists overcome the preconceptions they may have that all Gambians are 'after something' (cf. Diary Extract 9). Even once a relationship of sociability and trust is negotiated between hosts and tourists, the relationship continues to be asymmetrical and oriented towards ac- 
commodating the needs of the tourist: the interactions take place exclusively in the tourists' language, the power to define the relationship, e. g. to allow it to move from simple small talk on the street to 'friendship', however fleeting, and then to continue or terminate the relationship, lies firmly with the tourists.

We have described the interactions reported in this study in terms of commodified sociability, which places tourism firmly in the domain of consumption alongside shopping, eating out, visiting museums and galleries, attending sporting events, and so on (Urry 2002; Bauman 2000). Tourists, exemplified here by our informants, seem to be fast-tracked through 'culture shock' (Olberg 1979) on their arrival in The Gambia and during their first encounters with bumsters into friendship. They just have time to develop a certain level of cross-cultural awareness (Hanvey 1979) before it is time to leave again at the end of their visit, and seek another destination where the experience will be repeated. The thrill and enjoyment of the liminal (Turner 1969, 1974) experience of 'dipping a toe' in the margins of another culture is part and parcel of the promise and a necessary ingredient of a successful consumption of the exotic. Unable to achieve this goal on their own, tourists need to enlist the help of cultural brokers, who, in the case of Tha Gambia, offer themselves in the form of bumsters. An example of such relationship is manifest in the way some participants talk about their friend Malik as having been with them 'all the way through' (Interview Extract 3). He has helped them appreciate their dépaysement; they have consumed the product - The Gambia - and they can return home with a stock of narratives to relate to friends and family and thereby to enhance their global cultural capital. Moreover, this is an experience that can be repeated with each new destination that they visit. Malik, on the other hand, can only wait for new 'friends' to arrive.

Cardiff University

\section{Transcription conventions}

The extracts were transcribed using a simplified version of Jefferson's transcription conventions for spoken data (Maxwell Atkinson and Heritage 1999). The following conventions were used:

(.) short pause (half a second or less)

: lengthening

underline emphatic speech

[ simultaneously starting talk

[ ] overlapping talk 
$\begin{array}{ll}= & \text { contiguous talk } \\ - & \text { truncated word } \\ ? & \text { speech act having the illocutionary force of eliciting informa- } \\ \text { tion; also rising intonation }\end{array}$

\section{Acknowledgements}

The authors would like to thank all the participants who took part in this study, as well as Virpi Ylänne-McEwen and Nik Coupland for their comments on earlier drafts of this paper. We would also like to thank the Leverhulme Trust, who funded the research for this paper, Grant No. F/00 407/D to the Centre for Language and Communication Research, Cardiff University, for a larger project on Language and Global Communication: www.global.cf.ac.uk.

\section{Appendix}

Communication Diary for Gambia field trip 14-21 March 2002

As part of an ongoing research project on language and communication, we would like you to keep a record of the conversations you have with local people during the afternoon of Saturday 16 March (Period A) and the morning of Monday 18 March (Period B).

\section{Please complete each section of the grid.}

Time - morning, afternoon, etc is sufficient

Place - e. g. at (name of place) market, (name of place) beach, etc

Situation - e. g. buying a sandwich, asking the way

Person spoken to - e.g. market trader selling vegetables, male, approx. 30

Languages spoken - e.g. English and Wolof, gestures

Topics - greetings, buying a T-shirt, the weather, where I come from, family ...

What happened? - any additional interesting info

How did you feel about this interaction? - your evaluation of the conversation

At the end of each recording period, please spend 5-10 minutes reflecting on your overall impressions and reactions and make a note of these in the space provided.

Information about you:

Name (optional):

Age: Gender: 


\section{Languages known:}

All information will be used anonymously

Thank you very much for your time.

Sarah Lawson and Adam Jaworski

Centre for Language and Communication Research, Cardiff University

\section{References}

Appadurai, A. (1990). Disjuncture and difference in the global cultural economy. Theory, Culture and Society 7, 295-310.

Aston, G. (ed.) (1988). Negotiating Service: Studies in the Discourse of Bookshop Encounters. Bologna: CLUEB.

Bartlett, L. (2004). Expanding teacher work roles: a resource for retention or a recipe for overwork? Journal of Education Policy 19, 565-582.

Bauman, Z. (2000). Liquid Modernity. Cambridge: Polity.

Benthall, J. (1993). Disasters, Relief and the Media. London: I. B. Tauris.

Blommaert, J. (2003). Commentary: A sociolinguistics of globalization. Journal of Sociolinguistics 7, 607-623.

Bourdieu, P. (1991). Language and Symbolic Power. Edited and Introduced by J. B. Thompson. Translated by G. Raymond and M. Adamson. Cambridge: Polity Press.

Bourhis, R.Y. (1983). Language attitudes and self-reports of French-English usage in Quebec. Journal of Multilingual and Multicultural Development 4, 163-179.

- (1984). Cross-cultural communication in Montreal: Two field studies since Bill 101. International Journal of the Sociology of Language 46, 33-47.

Briggs, C. L. (1986). Learning How to Ask: A Sociolinguistic Appraisal of the Role of the Interview in Social Science Research. Cambridge: Cambridge University Press.

Brown, N. J. (1993). Tourism and tourist contact in Bakau: Aspects of socio-cultural change in a Gambian town. Unpublished PhD thesis, Hull University.

Coupland, J. (2000). Introduction: Sociolinguistic perspectives on small talk. In Coupland, J. (ed.), Small Talk. London: Pearson Education, 1-24.

Coupland, N. and V. Ylänne- $\mathrm{M}^{\mathrm{c} E w e n ~(2000) . ~ T a l k ~ a b o u t ~ t h e ~ w e a t h e r: ~ S m a l l ~ t a l k, ~}$ leisure talk and the travel industry. In Coupland, J. (ed.), Small Talk. Harlow: Longman/Pearson, 163-182.

Fishman, J. A. (1965). Who speaks what language to whom and when? La Linguistique 2, 67-88.

Gibbons, J. (1987). Code-Mixing and Code Choice: A Hong Kong Case Study. Clevedon: Multilingual Matters.

Goffman, E. (1967). Interaction Ritual: Essays on Face-to-Face Behavior. Garden City, New York: Anchor Press/Doubleday.

Graburn, N. H. H. (1989). Tourism: The sacred journey. In Smith, Valene L. (ed.), Hosts and Guests: The Anthropology of Tourism. $2^{\text {nd }}$ edition. Philadelphia: University of Pennsylvania Press, 21-36.

Halliday, M. A. K. (1978). Language as Social Semiotic: The Social Interpretation of Language and Meaning. London: Edward Arnold.

Hanvey, R. G. (1979). Cross-cultural awareness. In Smith, E. C. and L. Fiber Luce (eds.), Towards Internationalism: Readings in Cross-cultural Communication. Rowley, Massachusetts: Newbury House, 46-56. 
Held, D. and A. McGrew (eds) (2003). The Global Transformations Reader: An Introduction to the Globalization Debate. $2^{\text {nd }}$ edition. Cambridge: Polity Press.

Hymes, D. (1972). Models of the interaction of language and social life. In Gumperz, J. J. and D. Hymes (eds.), Directions in Sociolinguistics: The Ethnography of Communication. New York: Holt, Rinehart and Winston, Inc., 35-71.

Irvine, J. (1974). Strategies of status manipulation in the Wolof greeting. In Bauman, R. and J. Sherzer (eds.), Explorations in the Ethnography of Speaking. Cambridge: Cambridge University Press, 167-191.

Jamison, D. (1999). Tourism and ethnicity. The brotherhood of coconuts. Annals of Tourism Research 26, 944-967.

Jaworski, A., V. Ylänne-McEwen, C. Thurlow and S. Lawson (2003). Social roles and negotiation of status in host-tourist interaction: A view from British television holiday programmes. Journal of Sociolinguistics 7, 135-163.

Jaworski, A., S. Lawson and V. Ylänne-MEwen (forthcoming). Language, Tourism, Globalisation. London: Routledge.

Johnson, J. and B. Bytheway (2001). An evaluation of the use of diaries in a study of medication in later life. International Journal of Social Research Methodology 4, $183-204$.

Jones, K., M. Martin-Jones and A. Bhatt (2000). Constructing a critical, dialogic approach to research on multilingual literacy: participant diaries and diary interviews. In Martin-Jones, M. and K. Jones (eds.), Multilingual Literacies. Reading and Writing Different Worlds. Amsterdam: John Benjamins, 317-351.

Kuiper, K. and M. Flindall (2000). Social rituals, formulaic speech and small talk at the supermarket checkout. In Coupland, J. (ed.), Small Talk. London: Longman/ Pearson: 183-207.

Lakoff, R. (1974). What you can do with words: Politeness, pragmatics, and performatives. Berkeley Studies in Syntax and Semantics I, XVI-1-XVI-55.

Laver, J. (1981). Linguistic routines and politeness in greeting and parting. In Coulmas, F. (ed.), Conversational Routine: Explorations in Standardized Communication Situations and Prepatterned Speech. The Hague: Mouton, 289-304.

Lawson, S. (2002). Post-colonial patterns in global tourism. Paper presented at ICLASP 8, Hong Kong, 10-14 July 2002.

Lawson, S., and I. Sachdev (2000). Codeswitching in Tunisia: Attitudinal and behavioural dimensions. Journal of Pragmatics 32, 1342-1361.

Malinowski, B. (1923). The problem of meaning in primitive languages. In Ogden, C. K. and I. A. Richards (eds.), The Meaning of Meaning. London: Routledge and Kegan Paul, 146-152.

Maxwell Atkinson, J. and J. Heritage (1999). Jefferson's transcript notation. In Jaworski, A. and N. Coupland (eds.), The Discourse Reader. London: Routledge, $158-166$.

Morley, D. (1992). Television, Audiences and Cultural Studies. London: Routledge.

Oberg, K. (1979). Culture shock and the problem of adjustment in new cultural environment. In Smith, E. C. and L. Fiber Luce (eds.), Towards Internationalism: Readings in Cross-cultural Communication. Rowley, Massachusetts: Newbury House, 43-45.

Pennington, M., J. Balla, C. Detaramani, A. Poon and F. Tam (1992). Towards a Model of Language Choice among Hong Kong Tertiary Students: A Preliminary Analysis. (Research Report no.18). Hong Kong: City Polytechnic of Hong Kong, Department of English.

Romaine, S. (1983). Collecting and interpreting self-reported data on the language use of linguistic minorities by means of 'language diaries'. M.A.L.S. Journal 8, $3-30$. 
Sacks, H. (1972). On the analyzability of stories by children. In Gumperz, J. J. and D. Hymes (eds.), Directions in Sociolinguistics: The Ethnography of Communication. New York: Holt, Rinehart and Winston, 325-345.

Scollon, R. and S. Wong-Scollon (1990 [1981]). Athabaskan-English interethnic communication. In Carbaugh, D. (ed.), Cultural Communication and Intercultural Contact. Hillsdale, New Jersey: Lawrence Erlbaum, 259-286. [Originally published in 1981.]

Tannen, D. (1984). Conversational Style: Analyzing Talk among Friends. Norwood, N.J.: Ablex.

The Gambia Experience (2004-2005). The Gambia (brochure).

The Gambia Tourist Authority (2004). www.visitthegambia.gm consulted on 5 April 2004.

Thomas, J. (1985). Cross-cultural pragmatic failure. Applied Linguistics 4, 91-112.

Tracy, K. and N. Coupland (1990). Multiple goals in discourse: An overview of issues. In Tracy K. and N. Coupland (eds.), Multiple Goals in Discourse. Clevedon: Multilingual Matters, $1-13$.

Turner, V. (1969). The Ritual Process: Structure and Anti-structure. Chicago: Aldine.

- (1974). Dramas, Fields, and Metaphors: Symbolic Action in Human Society. Ithaca: Cornell University Press.

Ure, J. (1979). Language choice and socialisation in a multilingual community: Language use among primary school teachers in Ghana. In MacCormack, W. and S. A. Wurm (eds.), Language and Society: Anthropological Issues The Hague: Mouton, $263-283$.

Urry, J. (2002). The Tourist Gaze. $2^{\text {nd }}$ edition. London: Sage.

Wolfson, N. (1976). Speech events and natural speech: Some implications for sociolinguistic methodology. Language in Society 5, 189-209.

Youssouf, I. J., A. D. Grimshaw and C. S. Bird (1976). Greetings in the desert. American Ethnologist 3, 797-824. 